\title{
El turismo y su relación con el desarrollo sostenible del distrito de Cerro
} Azul, Cañete, 2013

\author{
Tourism and its relationship to sustainable development of Cerro Azul district, \\ Cañete, 2013
}

\author{
José Palacios ${ }^{1}$ Rafael Garay ${ }^{2}$
}

http://dx.doi.org/10.21503/CienciayDesarrollo.2014.v17i1.08

\section{RESUMEN}

La investigación realizada tuvo como problema: ¿Qué relación existe entre el turismo y el desarrollo sostenible del distrito de Cerro Azul, Cañete, 2013? Su objetivo es determinar la relación existente entre el turismo como actividad económica y el desarrollo sostenible en el distrito de Cerro Azul. La hipótesis de trabajo fue: Si en el turismo se aplica el paradigma de desarrollo sustentable, entonces el distrito de Cerro Azul lograría un balance favorable de efectos económicos, ambientales y sociales. El Universo de la investigación fue: los pobladores así como turistas visitantes del distrito. La muestra de la investigación: 18 turistas y 15 pobladores del distrito. El tipo de investigación es aplicada, cuyo diseño es no experimental, transversal-correlacional. El ámbito temporal del estudio fue el periodo 2013 y su ámbito espacial el distrito de Cerro Azul, provincia de Cañete y departamento de Lima. Se elaboró una encuesta que fue aplicada a 18 turistas y 15 pobladores del distrito de Cerro Azul para conocer su opinión acerca de la relación existente entre el turismo y el desarrollo sostenible. El turismo en un mundo globalizado se convierte en el medio auténtico para promover identidad y desarrollo, en el marco de un paradigma de sostenibilidad que proteja, conserve y difunda nuestra cultura por medios de los distintos atractivos y destinos turísticos de nuestro país, entre ellos el distrito de Cerro Azul, Cañete donde manteniendo la armonía entre lo económico, social y ambiental, se viene contribuyendo significativamente al mejoramiento de la calidad de vida y la satisfacción de necesidades de sus pobladores.

Palabras clave: Turismo sostenible.

\section{ABSTRACT}

The research had the problem: what is the relationship between tourism and the sustainable development of Cerro Azul District, Cañete, 2013? Its objective is to determine the relationship between the tourism as an economic activity and sustainable development in Cerro Azul District. The working assumption was: If the paradigm of sustainable development is applied in tourism, then Cerro Azul district achieved a favorable balance of economic, environmental and social effects. The universe of research was: residents as well as tourists visiting from Cerro Azul district. The sample of the research: 18 tourists and 15 residents of the district. The type of investigation is applied whose design is not experimental, transversal-correlational. The field temporary of study was the period 2013 and its spatial field of Cerro Azul district, province of Cañete and Department of Lima. It was a survey that was applied to 18 tourists and 15 residents of Cerro Azul district to know their opinion about the relationship between tourism and sustainable development. Tourism in a globalized world becomes in authentic environment to promote identity and development, within the framework of a paradigm of sustainability that protect,

1 Docente en la EAP de Turismo, Gastronomía y Hotelería.Doctor en Educación. 962290114. E-mail: uap_palacios@hotmail.com

2 Docente en la EAP de Turismo, Gastronomía y Hotelería.Doctor en Educación. 993313252. E-mail: rafaelantonio_01@hotmail.com 
preserve, and spread our culture by means of the different attractions and tourist destinations in our country, among them: Cerro Azul district, Cañete where maintaining harmony between economic, social and environmental, it is contributing significantly to the improvement of the quality of life and the satisfaction of needs of its residents.

Key words: Sustainable tourism.

\section{INTRODUCCIÓN}

El turismo como industria es un fenómeno que tiene una presencia creciente en la dinámica de nuestra economía nacional. Para muchas de las regiones y provincias del país constituye una de sus principales actividades generadoras de ingreso, empleo y desarrollo. El paradigma de desarrollo que se busca con el turismo y que fue motivo de esta investigación es el desarrollo sostenible.

Dentro de este contexto, el turismo se analiza como actividad económica que interacciona con el medio ambiente en un contexto de sustentabilidad. Se entiende por actividad económica la producción de bienes y servicios cuyo destino final es la satisfacción de las necesidades humanas.

Mochón (2004) sostiene: el turismo es la actividad realizada por las personas al desplazarse por diferentes motivos fuera de su lugar de residencia, por un periodo superior a 24 horas e inferior a un año. $Y$ esto incluye tanto al turismo realizado dentro del país, "turismo interior”, como al turismo que supone el desplazamiento fuera del propio país, "turismo exterior".

En la búsqueda de un paradigma de desarrollo sustentable, la economía ecológica, también conocida como teoría del desarrollo humano o economía del bienestar natural, juega un papel relevante al ser la ciencia de la gestión de la sustentabilidad. Su enfoque principal está en la sustentabilidad de las interacciones que se dan entre los subsistemas económicos y el macrosistema natural. Donde la sustentabilidad se entiende como la capacidad de la humanidad para vivir dentro de los límites ambientales.
Según Toffler (1980), los principios del industrialismo, y por extensión de la industria turística, con los que se lleva a cabo el diseño, desarrollo y operación del turismo son:

a) Uniformidad. Productos turísticos iguales, semejantes o idénticos, tales como cuartos de hotel, categoría y estrellas.

b) Especialización. Profesionalización y creciente división del trabajo para la prestación de servicios, como es el caso de recepcionistas, botones, amas de llaves, etcétera.

c) Sincronización. Actuación coordinada dentro de la empresa y en relación con otras empresas.

d) Concentración. Focalización del capital, de las inversiones y del trabajo, con objeto de ahorrar energía y aumentar la eficiencia.

e) Maximización. En donde lo grande se transforma en sinónimo de bueno y eficiente.

f) Centralización. Concentración del poder y de las decisiones.

Por otro lado, el producto turístico, según López y De León es entendido como cualquier atractivo que sirva para cautivar al viajero y convencerlo de que tome una decisión de compra. Los elementos del producto turístico se representan por una demanda, que se define como "el conjunto del público dispuesto a recurrir a los bienes y prestaciones de tipo turístico" por una oferta que se entiende como "la suma de bienes y prestaciones de servicios turísticos disponibles sobre el mercado". El producto turístico está compuesto por atractivos turísticos, planta turística, infraestructura de uso turístico, motivaciones, facilidades y accesibilidad. 
La OMT (2004), por medio de su Barómetro, reporta que el turismo es el sector más dinámico de la industria de servicios y uno de los más importantes en la economía global.

Sin lugar a dudas, el papel que desempeña el turismo en la economía es muy importante. Simplemente, en términos de participación, el turismo registró dentro de la "economía global", un incremento de $7 \%$ en 1990 , de $10 \%$ en 1999 , y se espera que alcance 15\% en el año 2020 (OMT, 2006).

Además, las estimaciones de la OMT establecen que los movimientos de turistas ascenderán a 1 600 millones de visitantes para el año 2020, lo que va a generar ingresos por más de dos mil millones de dólares anuales.

Los datos confirman que, en la actualidad y en el futuro próximo, el turismo será una actividad económica con una fuerte dinámica expansiva respaldada por las profundas transformaciones del proceso globalizador. Además, la globalización genera la aparición de nuevos destinos y el acercamiento de las distancias debido al abaratamiento del transporte y a la incorporación de nuevas tecnologías de información; modificando con ello el comportamiento de los individuos y las empresas con respecto al turismo.

Aun cuando el turismo es una actividad de gran impacto económico, esto no es suficiente. Puesto que para lograr un auténtico desarrollo, se requiere que el crecimiento económico sea superior al de la población y que se mejore su nivel de vida, para lo cual se vuelve necesaria una mejor distribución de la riqueza y la conservación del medio ambiente físico en que se sustenta (Méndez, 2003).

Por otra parte, el concepto de desarrollo no es sólo de índole económico, también es de carácter humano, y el concepto de desarrollo huma- no va más allá de la renta o ingreso per cápita, incluye el desarrollo de los recursos humanos y de las necesidades básicas como medida del progreso humano. Es por ello que, en un esfuerzo conciliador entre economía y medio ambiente, la Organización de las Naciones Unidas (ONU) formuló un concepto operacional denominado desarrollo sustentable, que integra de manera relacionada e interdependiente el medio ambiente, el desarrollo económico y el desarrollo social.

Así también, la Comisión Mundial para el Medio Ambiente y Desarrollo (CMMAD), publicada en el Informe Brundtland (Brundtland, 1987): Desarrollo sustentable es aquel desarrollo que satisface las necesidades del presente, sin comprometer la capacidad de las generaciones futuras para satisfacer las propias.

La gestión del turismo incluye una multiplicidad de elementos (comercialización, transportación, hotelería, alimentos y bebidas, infraestructuras y servicios), que vuelven importante orientar las fuerzas del mercado y la inversión, en relación con el medio ambiente, con la finalidad de desempeñar esta actividad económica en forma sustentable. El turismo sustentable, como actividad económica productiva, busca contribuir la continuación del sistema global y garantizar la sustentabilidad propia región en la que se desarrolla.

De acuerdo con González y León (1995) el desarrollo turístico sustentable es el conjunto de condiciones físicas, biológicas, sociales y económicas, que garantizan el mantenimiento de la productividad y el ingreso de la actividad turística para las futuras generaciones, y mantienen a la vez el nivel de satisfacción de los visitantes actuales y futuros así como de la población receptora.

Lo cual a su vez implica considerar, entre otros, los siguientes factores para lograr una presencia turística de mayor calidad que garantice la sustentabilidad del destino turístico: 
- La estancia promedio.

- Características de los turistas y anfitriones.

- Concentración geográfica de visitantes.

- Intensidad del periodo estacional.

- Gasto promedio per cápita.

- Ingreso promedio.

Cerro Azul es un distrito localizado dentro de la provincia de Cañete, a $131 \mathrm{~km}$ de la ciudad de Lima, cuenta con enorme potencial turístico, es un excelente destino para aquellos que busquen encontrarse con la naturaleza, tradiciones ancestrales, descansar del bullicio de las ciudades y disfrutar de sus hermosas playas.

Sin embargo, se hace necesario reflexionar sobre cierta problemática da por su expansión urbanística, la privatización de diversas playas, el crecimiento de la actividad turística que nos lleva a formularnos la siguiente interrogante: ¿Qué relación existe entre el turismo y el desarrollo sostenible del distrito de Cerro Azul, Cañete, 2013?

La investigación tuvo como objetivo determinar la relación existente entre el turismo como actividad económica y el desarrollo sostenible en el distrito de Cerro Azul en la provincia de Cañete durante el año 2013.

La hipótesis de trabajo fue: Si en el turismo se aplica el paradigma de desarrollo sustentable, entonces el distrito de Cerro Azul lograría un balance favorable de efectos económicos, ambientales y sociales.

El trabajo de investigación se justifica porque señala el respeto que debe existir entre el turista y la comunidad, y esboza la transcendencia que tiene para el desarrollo sostenible, la utilización racional de los recursos turísticos de la zona, de tal forma que éstos no se deterioren ni corran el peligro de desaparecer, y que puedan seguir siendo utilizados por las comunidades que viven de ellos y por las futuras generaciones.

\section{MATERIALES Y MÉTODOS}

a. Elementos de estudio

El universo de la investigación fueron: los pobladores así como turistas visitantes del distrito de Cerro Azul. La muestra de la investigación: 18 turistas y 15 pobladores del distrito de Cerro Azul. El Método de muestreo empleado fue el Aleatorio simple utilizando una muestra por conglomerados.

\section{b. Métodos, técnicas e instrumentos}

El tipo de investigación es aplicada, cuyo diseño es no experimental, transversal-correlacional. El ámbito temporal del estudio fue el periodo 2013 (Nov. - Dic.) y su ámbito espacial el distrito de Cerro Azul, provincia de Cañete y departamento de Lima.

Se elaboró una encuesta que fue aplicada a 18 turistas y 15 pobladores del distrito de Cerro Azul para conocer su opinión acerca de la relación existente entre el turismo y el desarrollo sostenible.

\section{RESULTADOS}

De la encuesta aplicada se obtuvieron los siguientes resultados:

\section{Encuesta: Turismo Sostenible en Cerro Azul}

\section{Turistas}

La siguiente encuesta nos permitirá visualizar la percepción de los turistas sobre el turismo sostenible. Está dirigida a los visitantes del distrito de Cerro Azul.

\section{Encuestados: 18}




\section{Género}

\begin{tabular}{lc} 
Masculino & 11 \\
Femenino & 7 \\
\hline
\end{tabular}

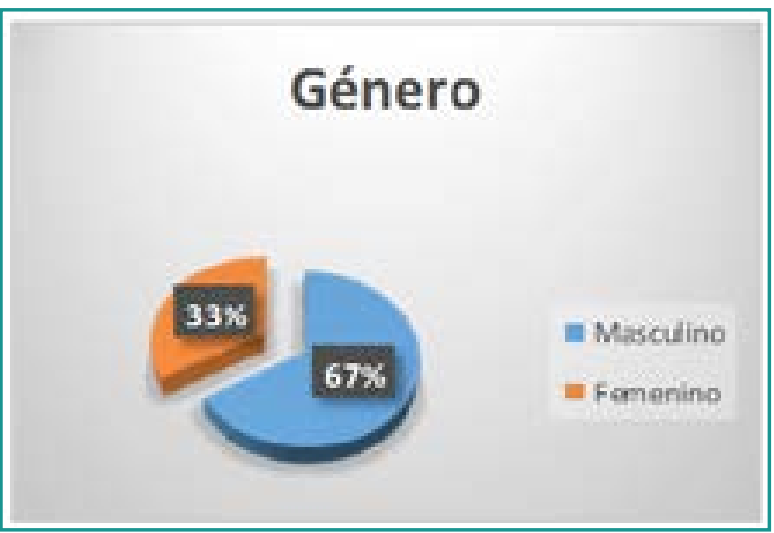

\section{Lugar de procedencia:}

\begin{tabular}{lc} 
Dentro Cañete & 10 \\
\hline Lima & 6 \\
\hline Interior País & 2 \\
\hline Extranjero & 0 \\
\hline
\end{tabular}

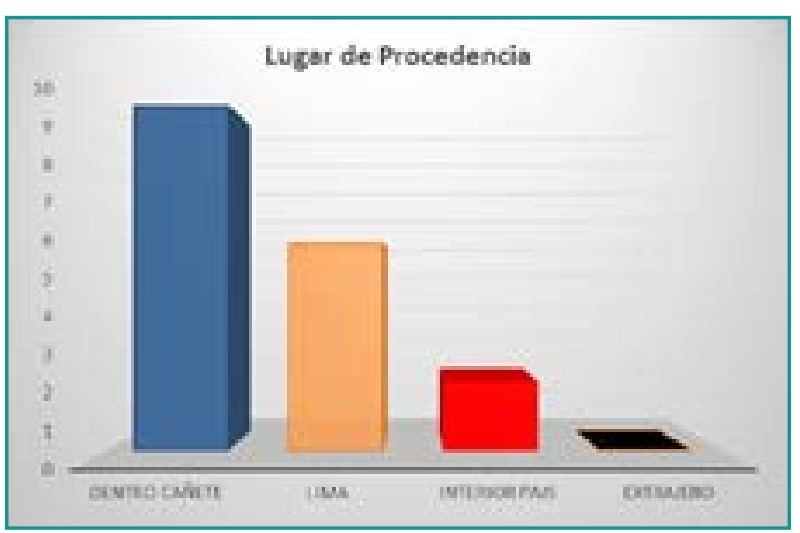

3. ¿Qué valora más de un destino turístico?

\begin{tabular}{cc}
\hline Cultura & 0 \\
Paisaje & 5 \\
\hline Seguridad & 0 \\
Clima & 1 \\
\hline Descanso & 12 \\
\hline
\end{tabular}

\section{¿Qué valora más de un destino turístico?}

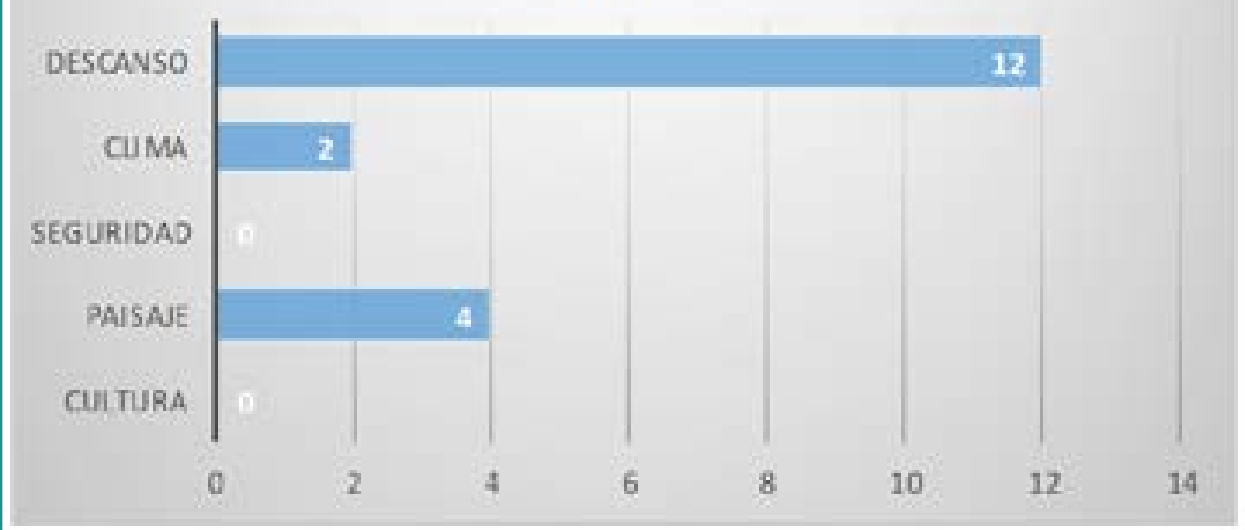




\section{4. ¿Al viajar que buscas del lugar en que te hospedas?}

Comodidad sin importar el medio ambiente

Antepones el precio al cuidado ambiental 3

Antepones el cuidado ambiental al precio 2

Calidad más responsabilidad

Ninguno

1

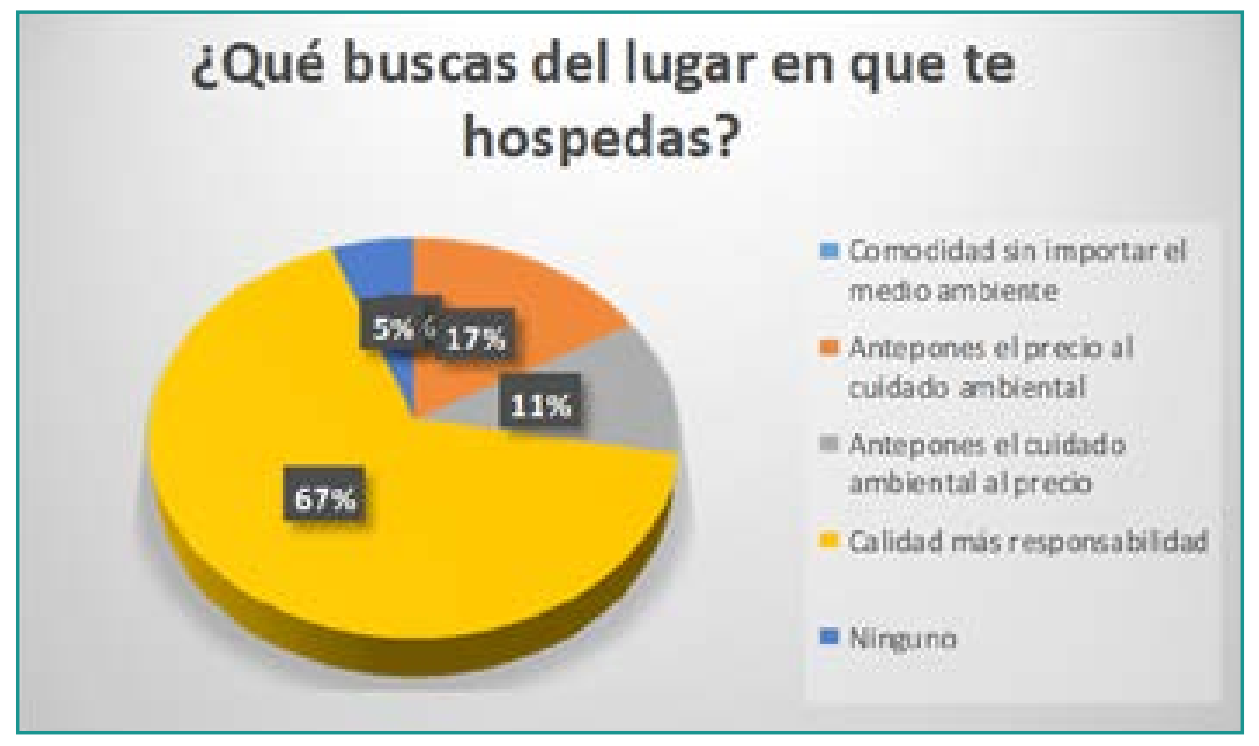

5. ¿Cuál es la razón por la que visitas este destino turístico?

\begin{tabular}{ll} 
Descanso & 8 \\
\hline Diversión & 1 \\
\hline Por el paisaje & 2 \\
Por sus playas & 5 \\
Otros & 2 \\
\hline
\end{tabular}

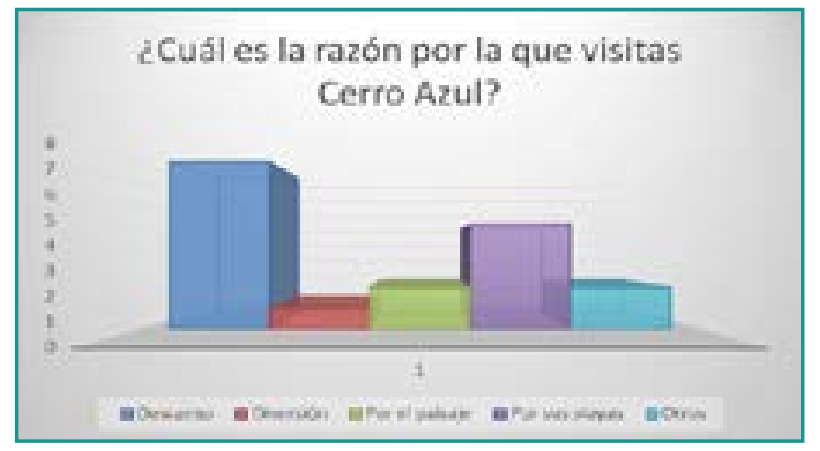

6. ¿Consideras importante que se desarrolle un turismo responsable con el medio ambiente?

\begin{tabular}{cc}
$\mathrm{Si}$ & 18 \\
$\mathrm{No}$ & 0 \\
\hline
\end{tabular}

LCorsidecas importaste que se desarrelie in thriumo respoesablo cos el medio ambiente?

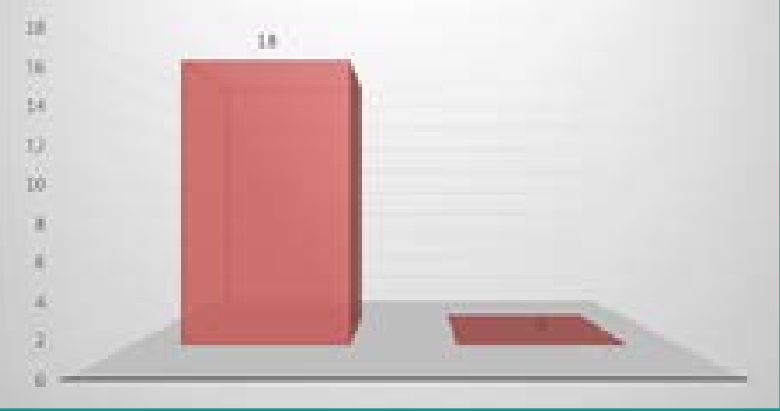




\section{7. ¿Cuál consideras que es el principal aporte de la actividad turística en esta zona?}

\begin{tabular}{lc}
$\begin{array}{l}\text { Ingresos económicos para el distrito y } \\
\text { empresarios }\end{array}$ & 1 \\
Método para combatir la pobreza & 2 \\
Método que incentiva la inclusión social & 2 \\
Método para dar a conocer el País & 0 \\
Desarrollo para la localidad & 13 \\
\hline Otros & 0 \\
\hline
\end{tabular}

\section{¿Cuál consideras que es el principal aporte de la actividad turistica en esta zona?}

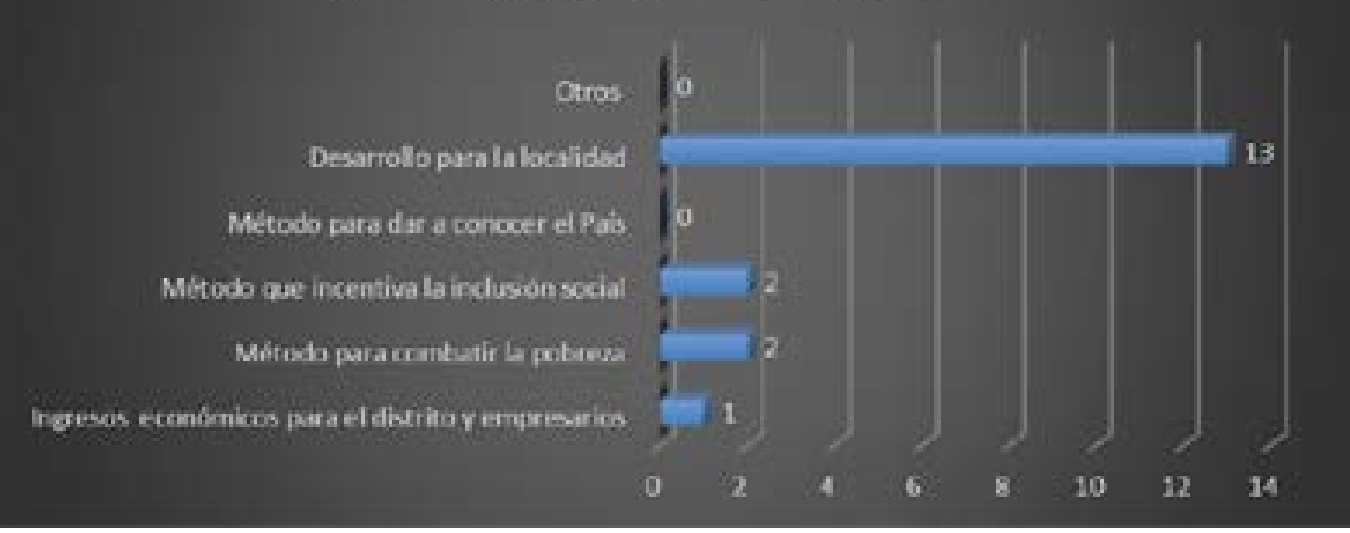

\section{8. ¿Qué sabes de turismo de sostenible?}

\begin{tabular}{lc} 
Actividad de extracción de recursos & 2 \\
Actividad económica que protege el & 10 \\
medio ambiente & 3 \\
Actividad turística rural & 3 \\
Actividad turística urbana & 0 \\
\hline Otros & \\
\hline
\end{tabular}

\section{¿Qué es turismo sostenible?}

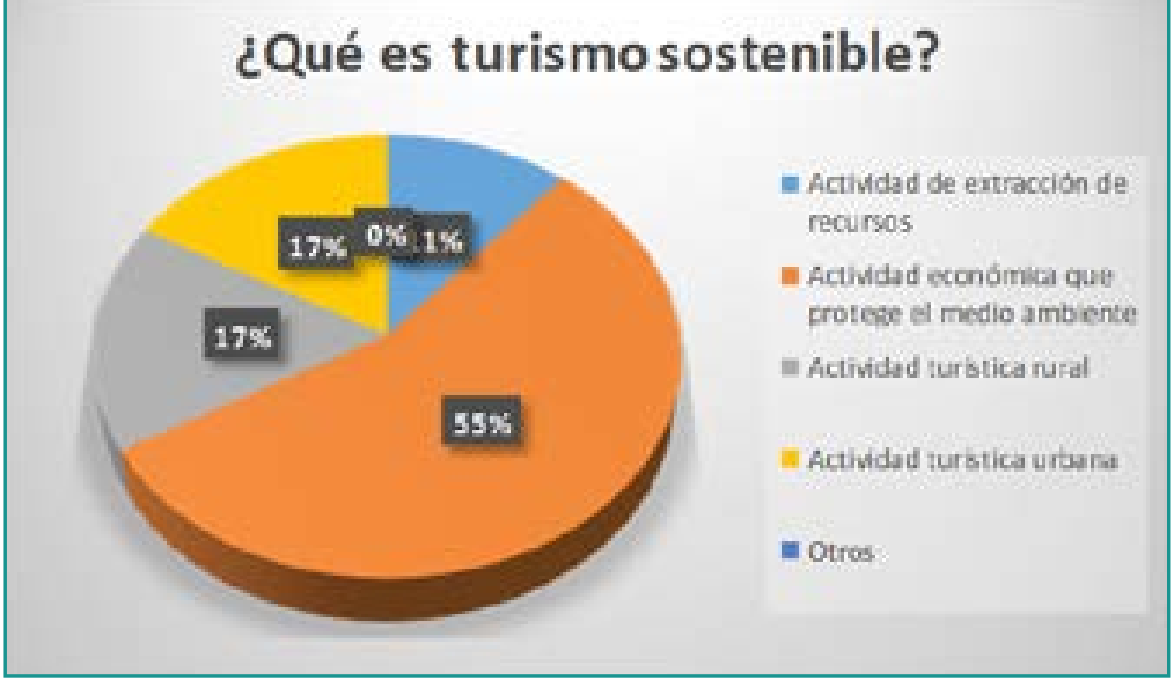


9. ¿Hasta qué punto te parece prioritaria la sostenibilidad para el futuro del sector turístico? (1-5)

\begin{tabular}{ll}
1 & 0 \\
2 & 1 \\
3 & 6 \\
4 & 3 \\
5 & 8 \\
\hline
\end{tabular}

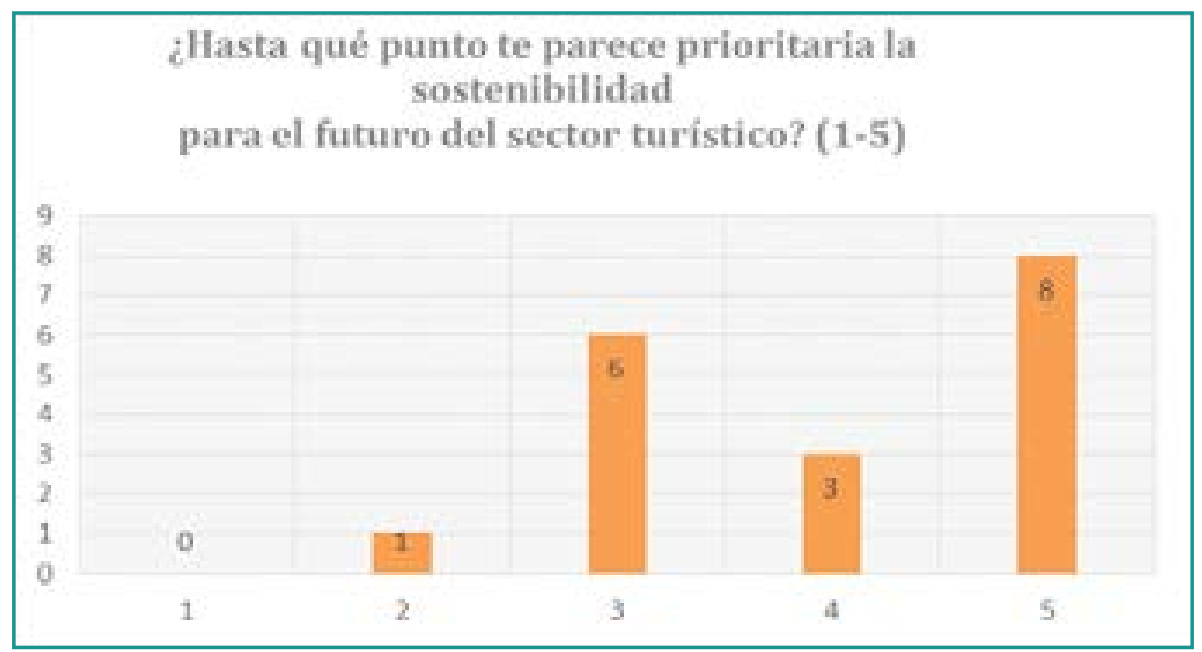

10. ¿Sabes si en el distrito hay en marcha iniciativas hacia un turismo más sostenible?

Eco museos, proyectos de custodia del territorio.

Rutas gastronómicas. 3

Rutas culturales. 2

Rutas Arqueológicas 1

Promoción de deportes Acuático $\quad 4$

No tengo conocimiento 5

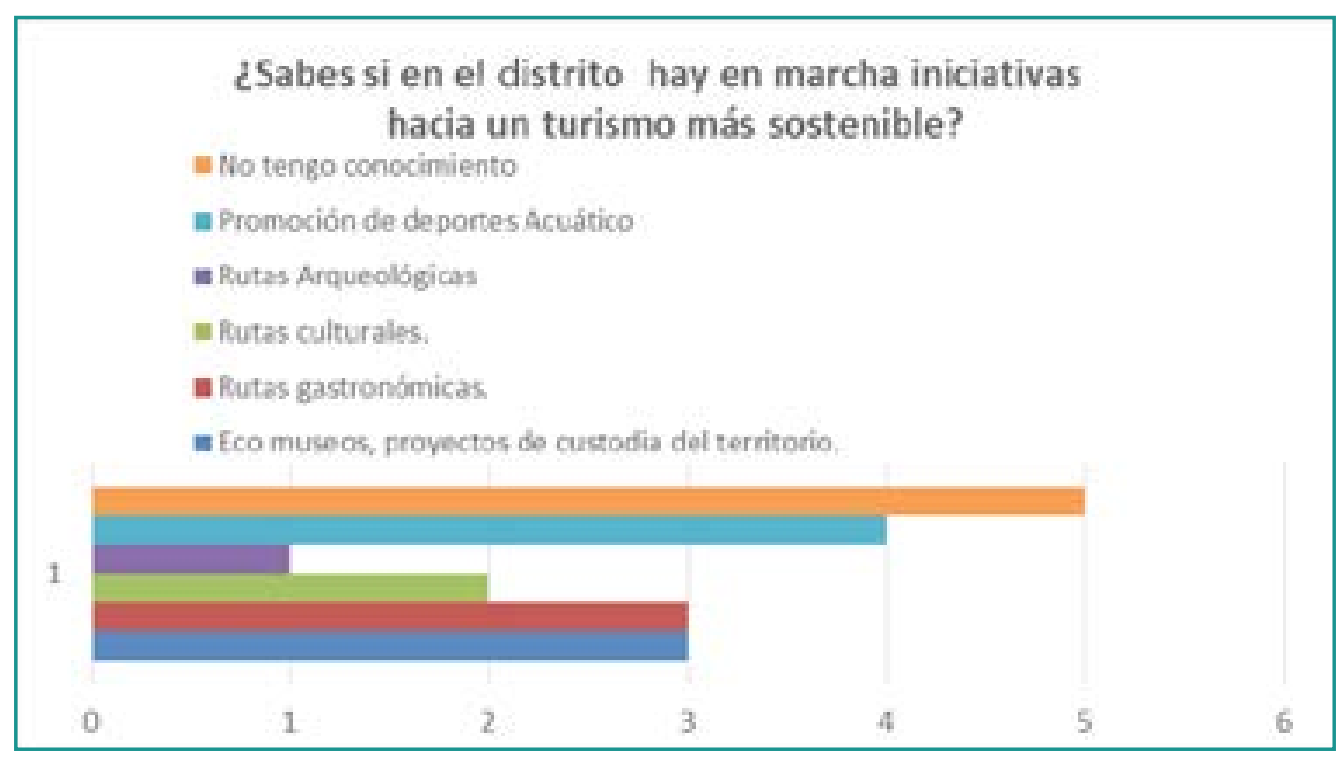




\section{Encuesta: Turismo sostenible en Cerro Azul}

\section{Pobladores del distrito}

La siguiente encuesta nos permitirá visualizar la percepción de los pobladores sobre el turismo sostenible.

\section{Encuestados: 15}

\section{Género}

\begin{tabular}{ll} 
Masculino & 7 \\
Femenino & 8 \\
\hline
\end{tabular}

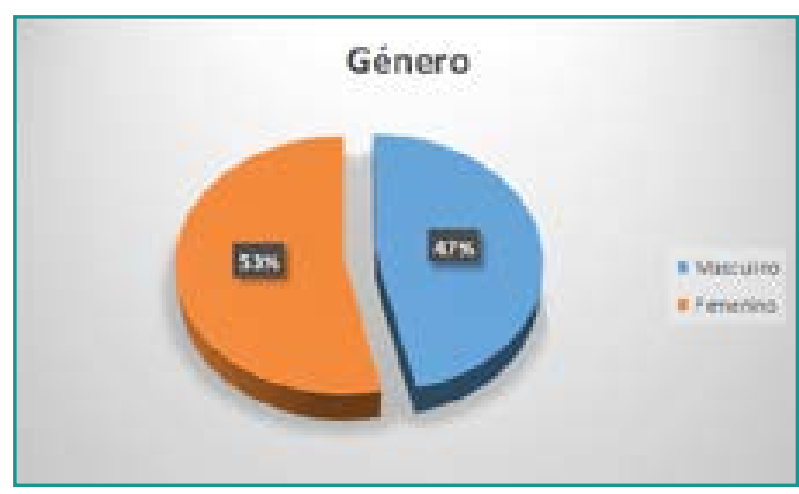

3. ¿Qué crees que más valoran de un destino turístico?

\begin{tabular}{|c|c|}
\hline Cultura & 1 \\
\hline Paisaje & 3 \\
\hline Seguridad & 0 \\
\hline Clima & 8 \\
\hline Descanso & 3 \\
\hline
\end{tabular}

\section{A qué se dedica}

\begin{tabular}{ll} 
Pesca & 4 \\
\hline Comercio & 2 \\
\hline Turismo & 5 \\
\hline Otros & 4 \\
\hline
\end{tabular}

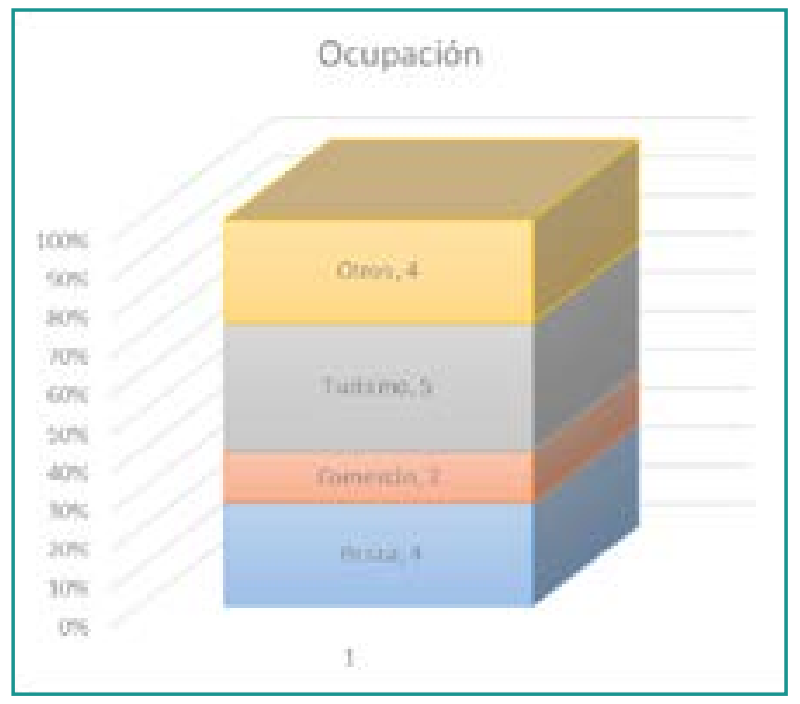

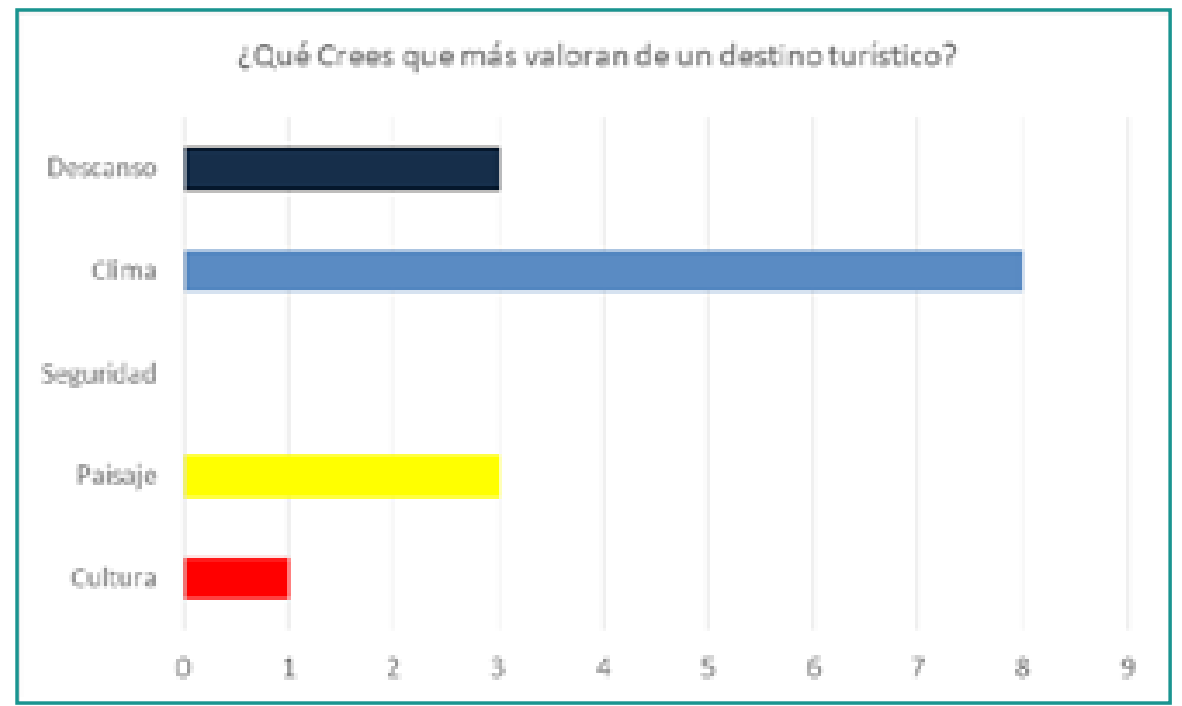




\section{4. ¿Consideras importante desarrollar un turismo responsable con el medio ambiente?}

\begin{tabular}{cc} 
Si & 13 \\
No & 2 \\
\hline
\end{tabular}

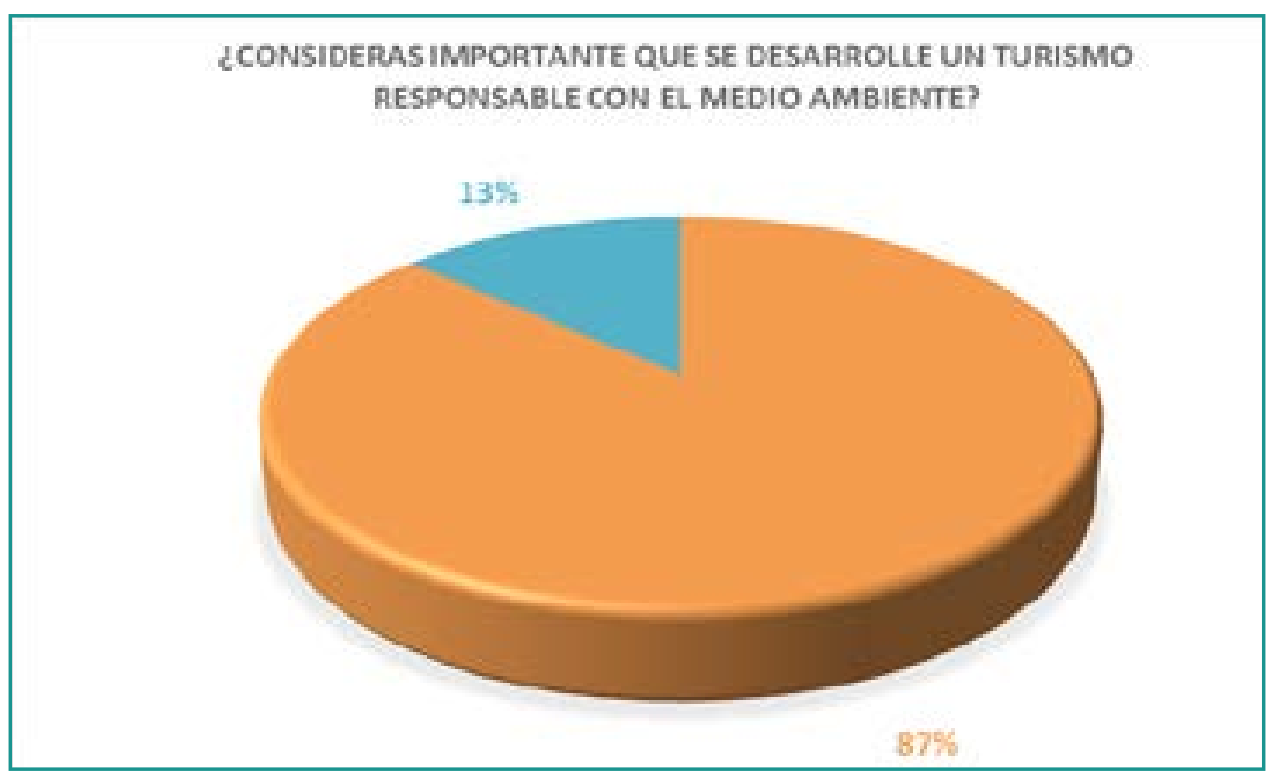

5. ¿Cuál consideras que es el principal aporte de la actividad turística?

\begin{tabular}{ll} 
Ingresos económicos para el distrito y empresarios & 6 \\
Método para combatir la pobreza & 0 \\
Método que incentiva la inclusión social & 1 \\
Método para dar a conocer el País & 0 \\
Desarrollo para la localidad & 8 \\
Otros & 0 \\
\hline
\end{tabular}

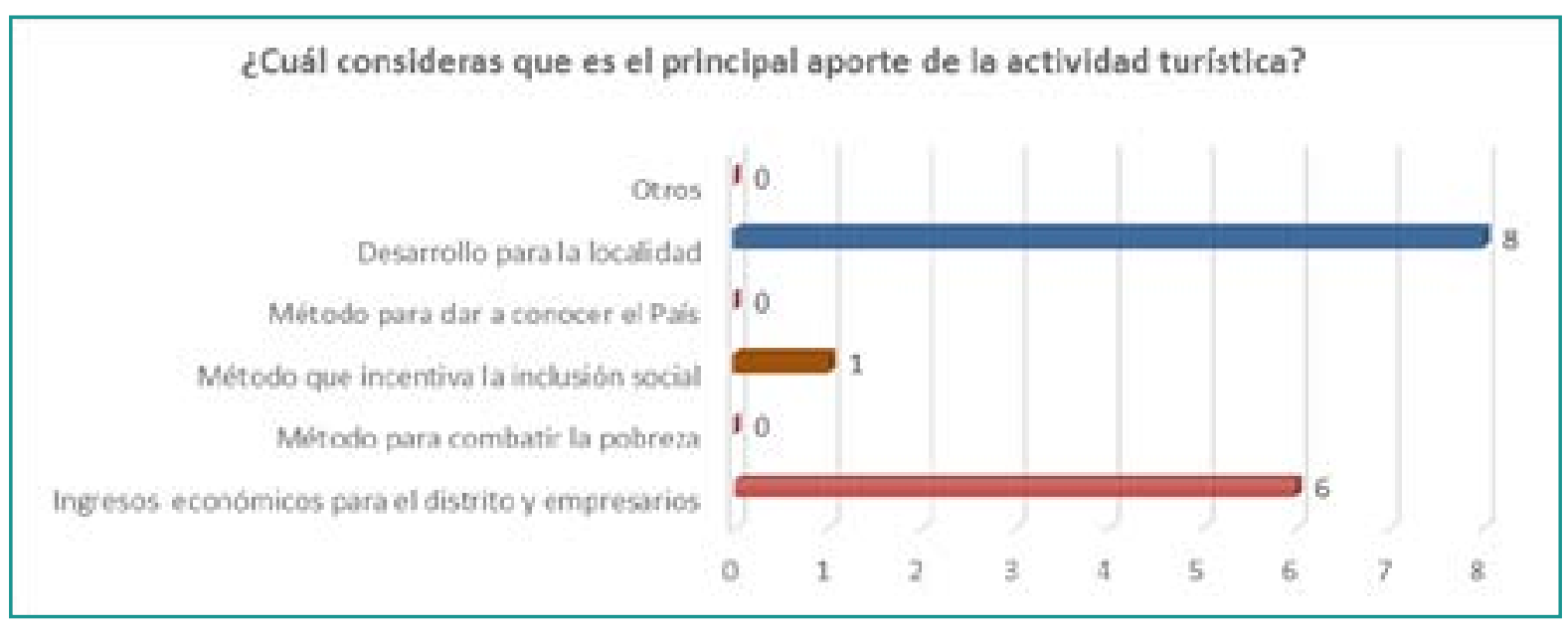




\section{6. ¿Cuál considerarías la principal desventaja del turismo?}

\begin{tabular}{ll} 
Beneficia a grandes empresas no a las pequeñas & 5 \\
Beneficia a empresas internacionales no nacionales & 0 \\
\hline Degrada el medio ambiente & 3 \\
Pérdida de Valores y costumbres de la autóctonas de la localidad & 1 \\
Aumento de Crimen & 4 \\
\hline Deterioro de sitios arqueológicos y turísticos. & 2 \\
\hline
\end{tabular}

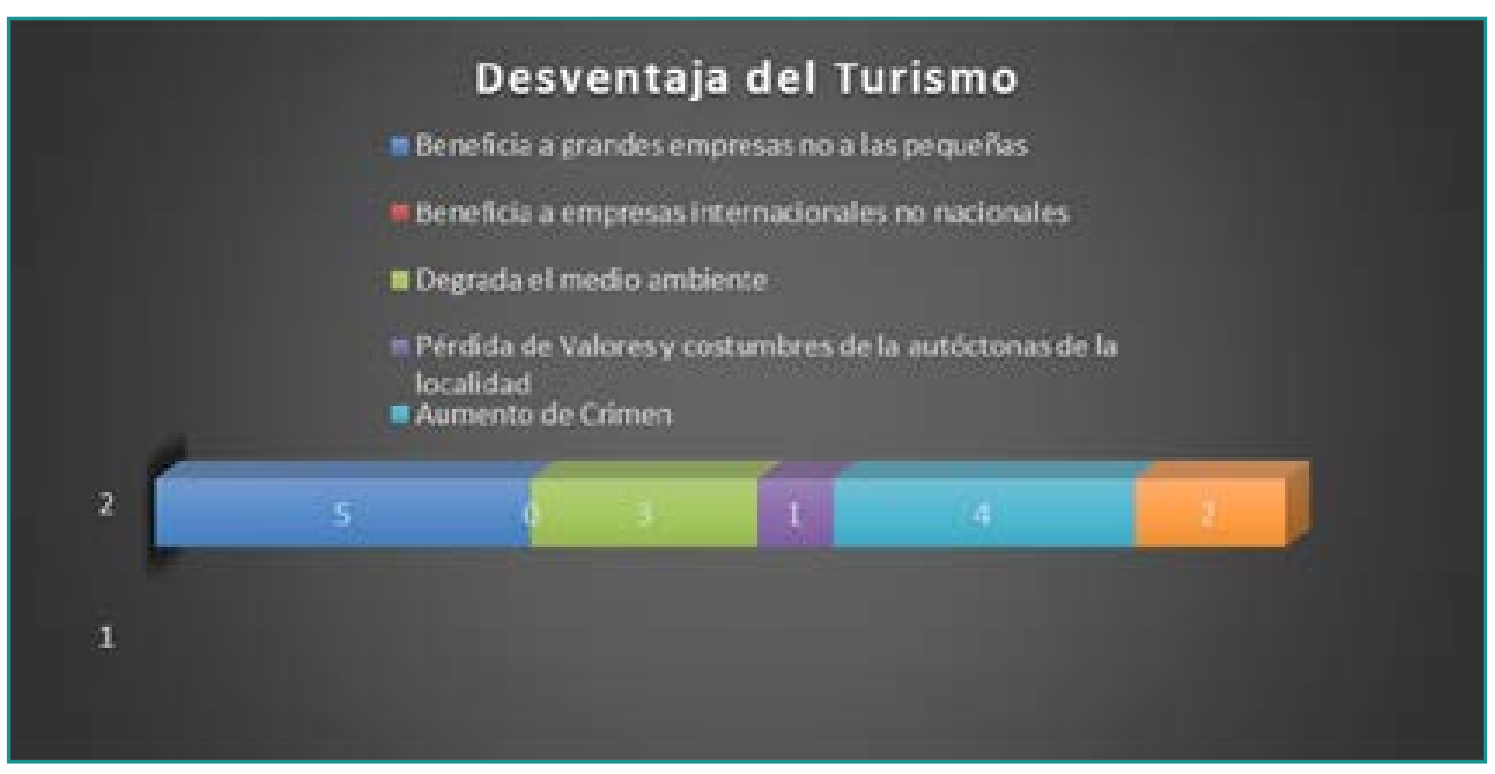

\section{7. ¿Qué sabes de turismo de sostenible?}

\begin{tabular}{ll} 
Actividad de extracción de recursos & 3 \\
Actividad económica que protege el medio ambiente & 8 \\
Actividad turística rural & 2 \\
Actividad turística urbana & 2 \\
Otros & 0 \\
\hline
\end{tabular}

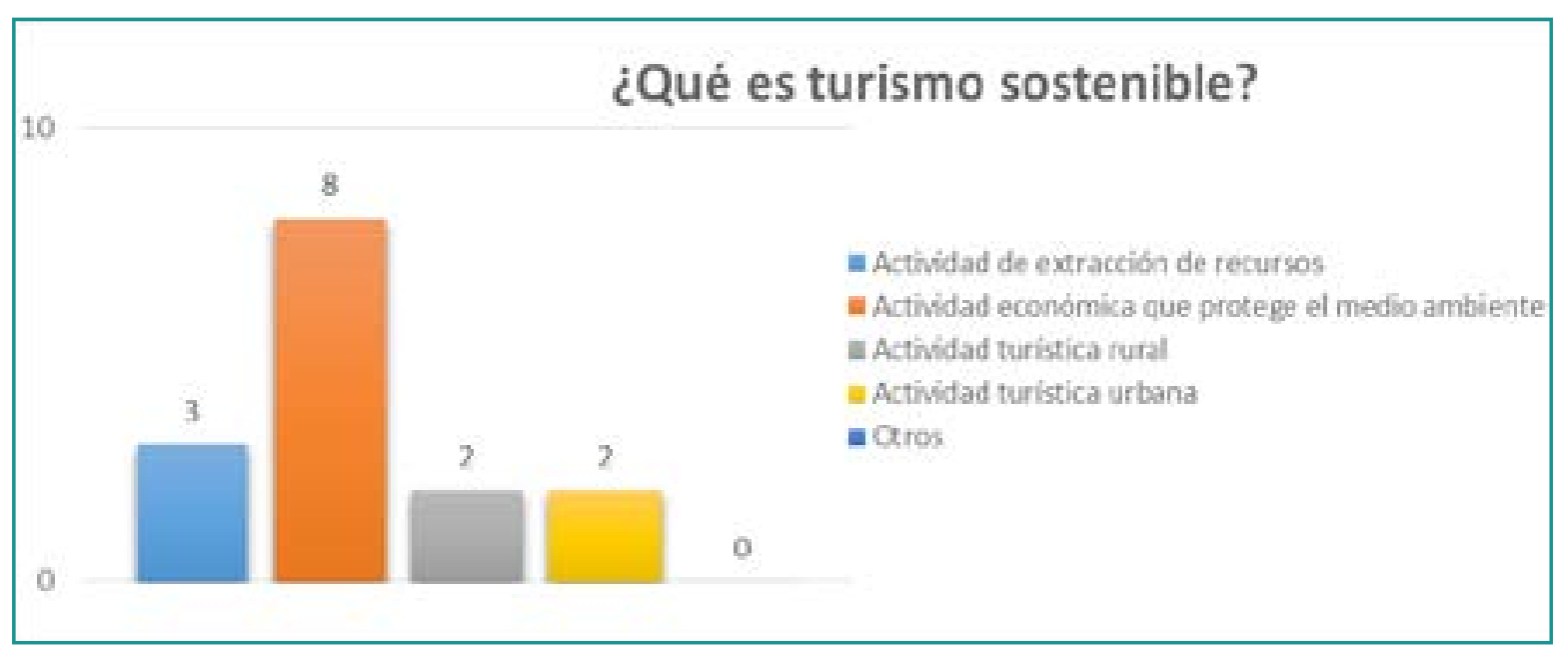


8. ¿Hasta qué punto te parece prioritaria la sostenibilidad para el futuro del sector turístico del Distrito? (1-5)

\begin{tabular}{ll}
1 & 1 \\
2 & 0 \\
3 & 2 \\
4 & 7 \\
5 & 5 \\
\hline
\end{tabular}

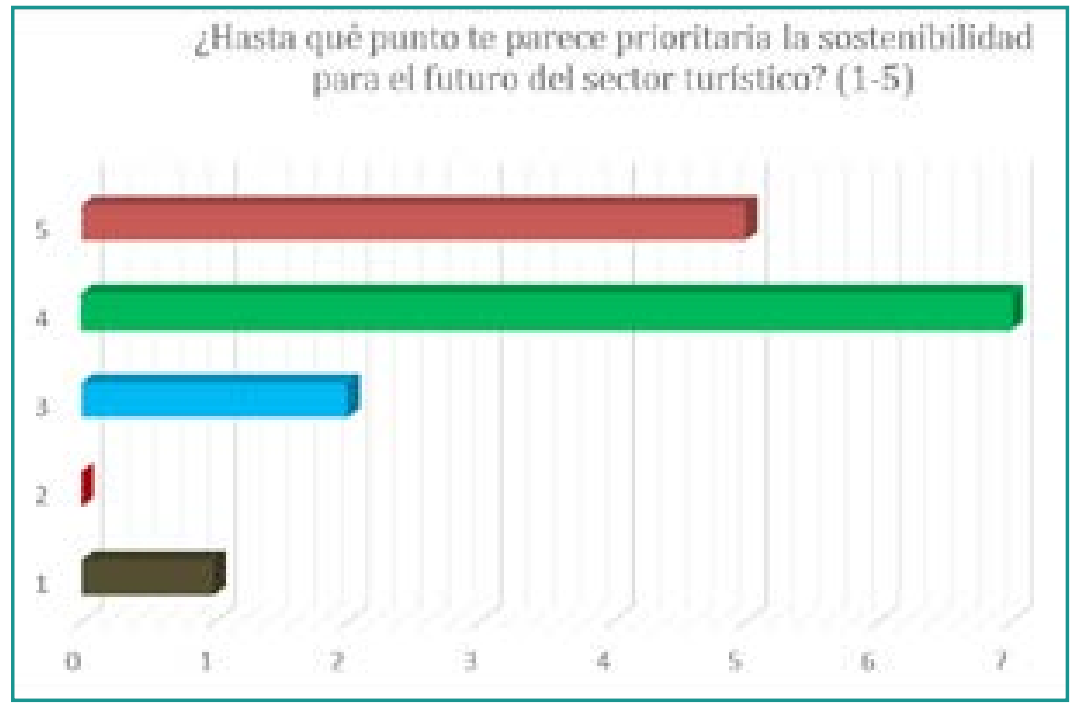

9. ¿Sabes si en el distrito hay en marcha iniciativas hacia un turismo más sostenible?

Eco museos, proyectos de custodia del territorio. $\quad 8$

Rutas gastronómicas.

Rutas culturales. $\quad 1$

Rutas arqueológicas $\quad 0$

Promoción de deportes Acuático 5

No tengo conocimiento 2

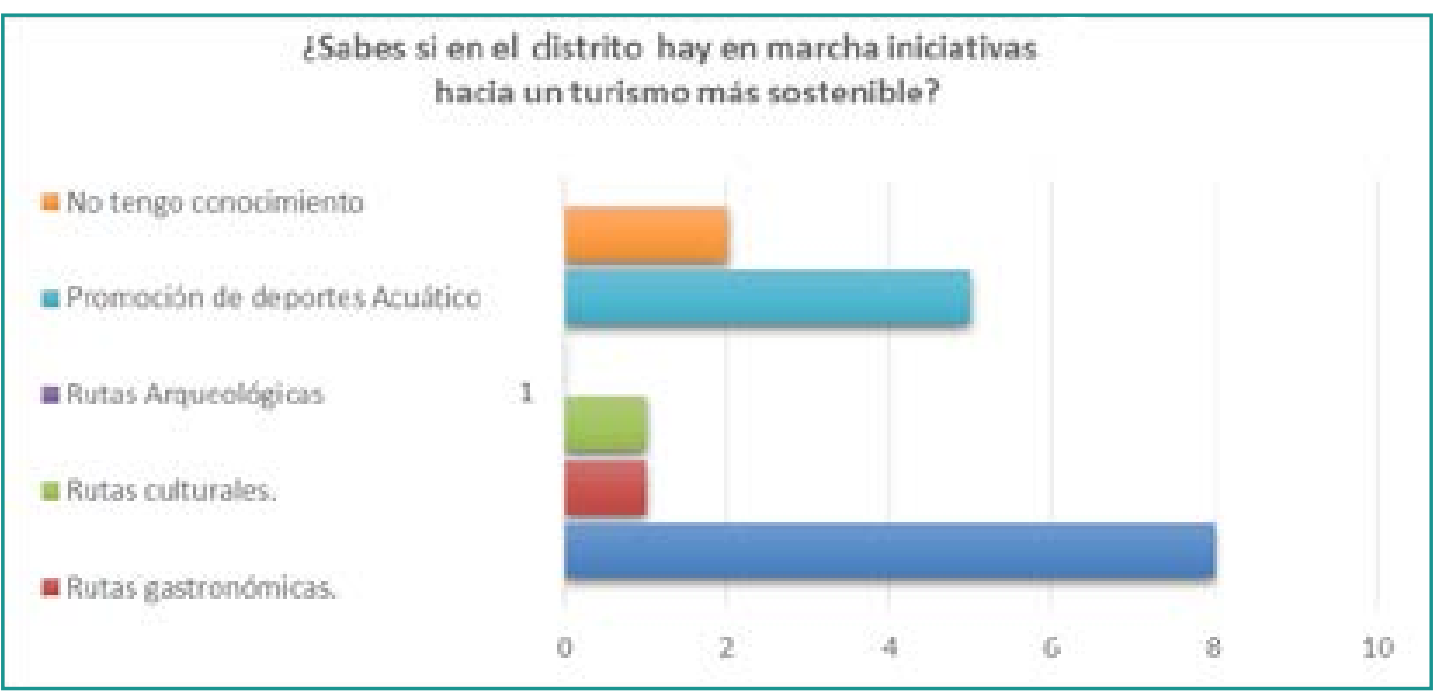


10. ¿Hasta qué punto te parecen útiles estos proyectos y como piensas que se podrían mejorar/ ampliar?

\begin{tabular}{ll} 
Plantearlo como una obligación Estado & 2 \\
Uniendo esfuerzos, cooperación. (adm. pública-privado-emprendedores) & 6 \\
\hline Es necesario el apoyo de los guías y empresas turísticas & 3 \\
\hline Lograr un equilibrio y conservar todos los componentes del producto turístico & 0 \\
\hline Hacer partícipes del turismo a los residentes. & 4 \\
\hline
\end{tabular}

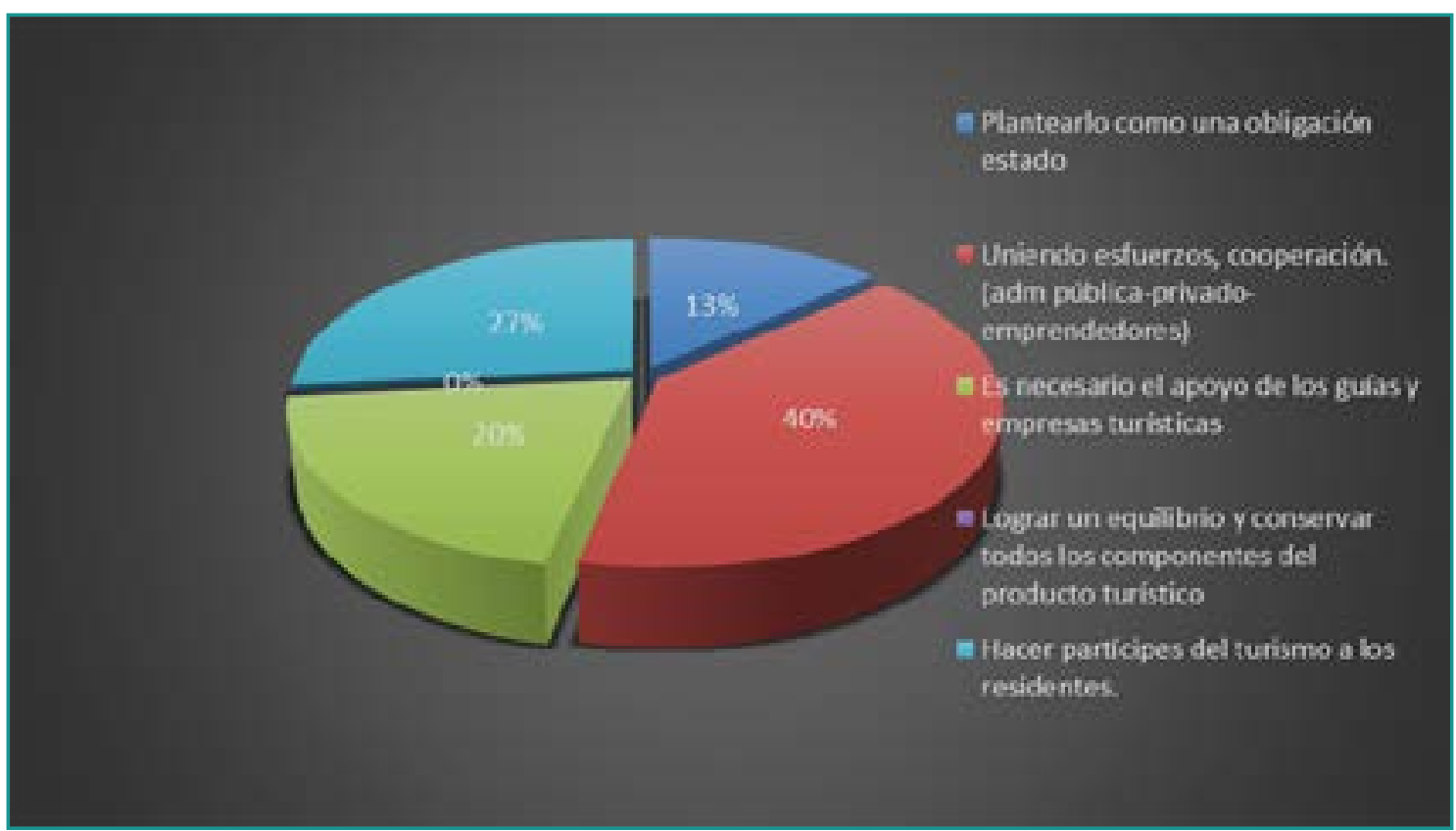

\section{DISCUSIÓN}

1. Un significativo $55 \%$ de los turistas encuestados manifiesta que el turismo sostenible es una actividad que protege el medio ambiente, muy por el contrario de la común apreciación que señala que muy pocos conocen el significado de sostenibilidad.

2. Por otro lado un $20 \%$ de turistas afirma desconocer si existen proyectos de desarrollo sostenible en Cerro Azul, pero un $40 \%$ valora la sostenibilidad del turismo.

3. Un 30\% de los pobladores de Cerro Azul se dedica al turismo pero que un gran porcentaje beneficia a las grandes empresas.

4. Un $60 \%$ de los pobladores manifiesta conocer proyectos de desarrollo sostenible en Cerro Azul, pero que es necesario unir esfuerzos para impulsarlo.

\section{CONCLUSIÓN}

El turismo en un mundo globalizado se convierte en el medio auténtico para promover identidad y desarrollo, en el marco de un paradigma de sostenibilidad que proteja, conserve y difunda nuestra cultura por medios de los distintos atractivos y destinos turísticos de nuestro país, entre ellos el distrito de Cerro Azul, Cañete donde manteniendo la armonía entre lo económico, social y ambiental, se viene contribuyendo significativamente al mejoramiento de la calidad de vida y la satisfacción de necesidades de sus pobladores.

\section{REFERENCIAS BIBLIOGRÁFICAS}

1. Brundtland, G. (1987) Nuestro futuro común: un resumen, F. Bellomo (trad.), México, Comisión

2. González, M. y C. León, (1995) Objetivos y politi- 
cas del desarrollo turístico sostenible, México. Centro Interdisciplinario de Investigaciones y Estudios sobre Medio Ambiente y Desarrollo.

3. López, D. y J. de León (2002) Empresas de viajes: apuntes, 4a. ed. México, Escuela Superior de Turismo/Instituto Politécnico Nacional.

4. Méndez, L. A. (2000) Desarrollo sustentable y estado global. Implicaciones para la administración pública: México como caso, tesis doctoral inédita, México, Universidad Autónoma de México.
5. Mochón, F. (2004) Economía y turismo, España, McGrawHill.

6. Organización Mundial del Turismo (OMT), (2004) Barómetro OMT del turismo mundial, volúmenes: 2-8 núms. 3, <http://www.unwto.org/ index_s.php $>$ [24 de marzo de 2010].

7. Toffler, A. (1980) La tercera ola, México, Plaza \& Janés, p. 33. 